\title{
PERFIL DOS EMPREENDEDORES INDIVIDUAIS E CARACTERÍSTICAS DOS NEGÓCIOS FORMALIZADOS PELO PROGRAMA EI EM ARACAJU, SERGIPE
}

\author{
PROFILE OF INDIVIDUAL ENTREPRENEURS AND CHARACTERISTICS OF FORMALIZED \\ BUSINESS BY EI PROGRAM IN ARACAJU, SERGIPE
}

Recebido em 21.01.2013. Aprovado em 28.05.2013

Avaliado pelo sistema double blind review

DOI: http://dx.doi.org/10.12712/rpca.v7i2.255

\section{Marco Otávio dos Santos Vianna}

motavio01@yahoo.com.br

Mestrado em Administração - PROPADM - Universidade Federal de Sergipe - UFS - São Cristóvão - SE - Brasil

\section{Rivanda Meira Teixeira}

rivandateixeira@gmail.com

Mestrado em Administração - PROPADM - Universidade Federal de Sergipe - UFS - São Cristóvão - SE - Brasil

\section{Veruschka Vieira Franca}

veruschkafranca@gmail.com

Mestrado em Administração - PROPADM - Universidade Federal de Sergipe - UFS - São Cristóvão - SE - Brasil

\section{Resumo}

A partir de uma ação unificada em todo o país, passou-se a oferecer condições especiais para os empreendedores individuais para que seus negócios fossem formalizados. Este estudo tem como objetivo delinear o perfil dos empreendedores individuais e definir as características dos empreendimentos formalizados através do Programa Empreendedor Individual EI em Aracaju, Estado de Sergipe. Foi realizado survey com amostra de trezentos Empreendedores Individuais que aderiram ao programa desde a sua criação em Sergipe em junho de 2009. As informações foram coletadas por meio de questionários estruturados aplicados pessoalmente com os empreendedores. Os dados foram analisados por meio de estatística descritiva e os resultados foram comparados ao de outras pesquisas realizadas no Brasil relacionadas ao programa EI. Pode-se destacar a participação feminina entre os empreendedores individuais de Aracaju, a escolaridade se mostrou bem distribuída e tem baixa renda mensal. Em relação aos empreendimentos, são predominantes no setor do comércio, contam com ajuda de uma ou mais pessoas, foram poucos os empreendimentos que surgiram recentemente e o negócio, mais do que uma fonte de renda individual, é sustento dos familiares.

Palavras-chave: Negócios informais. Empreendedor individual. Programa Empreendedor Individual em Sergipe.

\begin{abstract}
From a unified action across the country, it was offered to individual entrepreneurs special conditions for business be formalized. This study has the objective to draw entrepreneurs profile and define the characteristics of formalized businesses through the EI Program in Aracaju, Sergipe State. Survey was conducted with three hundred Individual Entrepreneurs who joined the program since its inception in Sergipe, June 2009. The information was collected through structured questionnaires applied personally with entrepreneurs. Data were analyzed through descriptive statistics and the results were compared to other research on the same program carried out in Brazil. You can highlight the female participation among the individual entrepreneurs of Aracaju, schooling was well distributed and they have lower monthly income. With respect to business, they are predominant from trade sector, count with the help of one or more persons, only a few of them have emerged recently and the business, more than a single source of income, is the family income.
\end{abstract}

Keywords: Informal Business. Individual Entrepreneur. Individual Entrepreneur Program in Sergipe. 


\section{PERFIL DOS EMPREENDEDORES INDIVIDUAIS E CARACTERÍSTICAS DOS NEGÓCIOS FORMALIZADOS PELO PROGRAMA EI EM ARACAJU, SERGIPE}

\section{Introdução}

As micro e pequenas empresas cumprem um papel fundamental no contexto econômico e social do país, pois atuam em atividades econômicas de baixa produtividade e absorvem mão de obra pouco qualificada e descartada pelos mercados formais, além de possuírem baixo custo para os investimentos iniciais e de funcionamento (KANTIS, ISHIDA e KOMORI, 2002; OYELARAN-OYEYINKA e LAL, 2004; VIOTTI, 2004).

Apesar da expressividade dos MPEs, a situação dessas empresas é preocupante quando analisados os dados apresentados pelo estudo Taxa de Sobrevivência das Empresas no Brasil, realizado pelo SEBRAE (2011b), o qual demonstrou que a cada 100 empresas que abrem 27 fecham as portas em menos de dois anos, resultado esse que chama a atenção mesmo sendo inferior ao de países exemplos de atividade empreendedora tal qual é a Itália. No Nordeste, a taxa é ainda maior, chegando a 30,9\% das MPEs com até dois anos de funcionamento, o que revela, portanto, as vulnerabilidades a que esses empreendimentos estão expostos, principalmente nos primeiros anos de funcionamento. Apesar das dificuldades, Souza e Mazalli (2008) argumentam que a pequena empresa é tida como um segmento singular no conjunto das unidades produtivas, apresentando uma atuação continuada nos espaços produtivos delimitados e contribuindo nas mais variadas formas e intensidades das cadeias produtivas.

De acordo com os dados do Ministério da Fazenda (2010), existem 10.335.962 (dez milhões, trezentos e trinta e cinco mil, novecentos e sessenta e dois) empreendimentos informais. A Lei $\mathrm{n}^{0} 128 / 2008$ teve por objetivo tirar da informalidade diversos micros empreendimentos e trabalhadores autônomos, oferecendo benefícios previdenciários e tributários, diminuindo a burocracia para o registro do negócio e garantindo as condições ofertadas pela Lei $\mathrm{n}^{0} 123 / 2006$, que criou o Estatuto das Micro e Pequenas Empresas. 0 Programa Empreendedor Individual- EI, por meio de instituições como o SEBRAE e a Junta Comercial, em suas unidades regionais, ofereceu, assim, suporte para auxiliar os empreendedores rumo à formalização. O Programa EI já formalizou mais de 2,5 milhões de empreendedores, dos quais, em Sergipe estão 9.078 (nove mil e setenta e oito) empreendimentos formalizados desde o início do Programa, de modo que há estimativas para que em todo o Brasil existam em 2014 mais empreendedores individuais do que MPEs (SEBRAE, 2012).

A formalização de empreendimentos e dos trabalhadores autônomos gera benefícios ao trabalhador como o amparo social previdenciário, o reconhecimento do seu negócio perante a sociedade e o acesso a programas de apoio para o seu negócio, gerando, ademais, benefícios ao Governo, que passa a recolher mais impostos e a ter acesso a informações para a elaboração de políticas específicas de apoio a esse setor produtivo. Também beneficia a sociedade, que pode desfrutar de produtos e serviços com procedência e lutar pelos seus direitos quando esses produtos e serviços não atendam à legislação vigente (SEBRAE, 2012).

Diante do contexto esse estudo tem por objetivos delinear o perfil dos empreendedores e caracterizar os empreendimentos do Programa EI em Aracaju, Sergipe. Inicialmente será realizado uma breve revisão sobre a economia informal,

\section{Economia informal}

Krein e Proni (2010), em seu estudo publicado pela própria OIT, reconsideram a nomenclatura dos termos "formal" e "informal", substituindo-os por "setor tradicional" e "setor moderno", respectivamente, sendo esse último entendido como um fenômeno moderno decorrente do processo de urbanização. Os autores explicam, ainda, que a definição do 
fenômeno vem sendo ampliada e revista à medida que o debate acadêmico avança e que novas circunstâncias econômicas, políticas e sociais acrescentam novos elementos e novas questões para discussão.

Para o SEBRAE (2007), as atividades informais compreendem as unidades econômicas pertencentes aos trabalhadores por conta própria e aos empregadores com até cinco empregados, incluindo todos os proprietários (sócios) desses empreendimentos. Já para Tiryaki (2008), os empreendimentos do setor informal se caracterizam pela pouca produtividade e acesso restrito a crédito. Silva et al. (2010) explicam que o conceito de setor informal aparece como um instrumento explicativo para um fenômeno histórico que é a existência de atividades econômicas de baixa produtividade e que se desenvolvem à margem da legislação.

Descrevem Gomes, Freitas e Júnior (2005) que o trabalho informal pode ser caracterizado pela produção em pequena escala, pelo reduzido emprego de técnicas e por não apresentar uma separação clara entre o capital e o trabalho, além de exercer atividades econômicas à margem da lei e desprovidas de proteção ou regulamentação pública.

Segundo o Ministério do Trabalho e Emprego (MTE, 2002), a elevação da informalidade no mercado de trabalho tem como fatores explicativos: 1) as novas formas de produção e de relações de trabalho, que aumentam o contingente de trabalhadores autônomos, por exemplo, por meio do processo de terceirização; 2) a realocação de mão de obra de setores tradicionalmente com maior grau de formalização (indústria de transformação) para setores com maior grau de informalidade (serviços e comércio) - terceirização do emprego; e 3) fatores institucionais associados ao sistema de seguridade social e à legislação trabalhista, incentivando o estabelecimento de relações informais de trabalho entre as empresas e os trabalhadores.

De acordo com Cacciamali (1983), a economia informal surge como consequência do modelo de produção capitalista, que na busca por diminuir custos dos fatores de produção, visam trabalhar com excedentes de mão de obra. Esse posicionamento cria desequilíbrios na relação de oferta de vagas e crescimento demográfico, de modo que essa relação também é influenciada por fatores como a distribuição populacional entre as zonas urbana e rural e a distribuição de renda per capita.

Já para Silva et al. (2010), o mercado informal brasileiro surge em função do alto comprometimento do trabalho formal que resulta na perda do dinamismo econômico e do desemprego originado por inovações tecnológicas ou por períodos econômicos recessivos. Contudo, a informalidade emerge como uma alternativa à geração de renda e de sustentabilidade para grupos excluídos, seja pela incapacidade técnica, seja pela oferta excedente de mão de obra no mercado de trabalho.

Segundo Tiryaki (2008), esse fenômeno ocorre em função das características dos empreendimentos informais, ou seja, dificuldades de acesso a crédito, de alavancagem financeira, baixo investimento inovativo, baixa produtividade da mão de obra e grande dependência dos setores formalizados, que tendem a retrair suas operações em períodos recessivos.

Em seu estudo, Schneider (2008) identificou os principais fatores que influenciam no aumento da economia informal e pode-se observar que a maioria dos fatores citados pelos empreendedores faz referência a fatores associados a custos, como são os casos de: aumento de tributos (39\%); falta de vontade de pagar impostos (25\%) e intensidade da regulação governamental. Schneider (2008) afirma, ainda, que as intervenções fiscais têm forte influência nas decisões dos empreendedores sobre o custo/benefício das ações, pois acresce o custo de oportunidade e diminui a possibilidade de lucro do empreendimento.

De acordo com Silva et al. (2010), o tamanho do mercado informal será determinado por 


\section{PERFIL DOS EMPREENDEDORES INDIVIDUAIS E CARACTERÍSTICAS DOS NEGÓCIOS FORMALIZADOS PELO PROGRAMA EI EM ARACAJU, SERGIPE}

variáveis institucionais, como tradição, respeito ao sistema legal e controle da corrupção. Portanto, a dimensão da informalidade depende da atuação estatal que pode trabalhar em três dimensões: econômica, fiscal e tributária.

Descreve Cacciamali e Braga (2002), que o crescimento do mercado informal tem consequências que podem ser observadas através do agravamento dos problemas sociais decorrentes da massa de trabalhadores não absorvidos pelo mercado de trabalho. Afirma ainda a referida autora que, a partir dos anos 70, os pesquisadores passaram a analisar, com maior interesse, os fatores de sustentabilidade econômica dos países em desenvolvimento, pois os modelos analíticos utilizados até aquele período apresentavam limitações por considerar apenas os meios tradicionais de produção e comercialização como geradores de riquezas, excluindo quaisquer outros fatores que não estivessem contabilizados formalmente.

Segundo o Instituto Brasileiro de Ética Concorrencial - ETCO e do Instituto Brasileiro de Economia da Fundação Getúlio Vargas - IBRE/FGV (2011), em 2011, a economia informal representou 17,2\% do Produto Interno Bruto (PIB); em números absolutos seriam $\mathrm{R} \$ 653.417$ (seiscentos e cinquenta e três milhões e quatrocentos e dezessete mil reais). Esses dados são representativos, pois refletem também o déficit fiscal que o Estado deixa de arrecadar com essa movimentação econômica não registrada, causando impactos negativos, uma vez que esses mesmos trabalhadores informais continuam fazendo uso da estrutura do Estado para amenizar as suas carências.

Mattos e Ogura (2009) afirmam que o setor informal representa uma grande parcela da economia dos países emergentes, e o seu crescimento tem origem na elevada carga tributária que esses países impõem aos pequenos produtores. Assim, os autores asseguram que a participação da economia informal na produção é bastante significativa, e essa presença influencia diretamente o desempenho da economia como um todo. Tal afirmação pode ser observada através do estudo realizado pelo Instituto Brasileiro de Ética Concorrencial - ETCO e do Instituto Brasileiro de Economia da Fundação Getúlio Vargas - IBRE/FGV (2011), que expõem o percentual de participação da economia informal no PIB, conforme disposto na Tabela 01:

Tabela 01: Percentual de Participação da Economia Informal no PIB do Brasil

\begin{tabular}{cc}
\hline Ano & Percentual de participação da Economia Informal no PIB \\
\hline $\mathbf{2 0 0 3}$ & $21,0 \%$ \\
$\mathbf{2 0 0 4}$ & $20,9 \%$ \\
$\mathbf{2 0 0 5}$ & $20,4 \%$ \\
$\mathbf{2 0 0 6}$ & $20,2 \%$ \\
$\mathbf{2 0 0 7}$ & $19,5 \%$ \\
$\mathbf{2 0 0 8}$ & $18,7 \%$ \\
$\mathbf{2 0 0 9}$ & $18,5 \%$ \\
$\mathbf{2 0 1 0}$ & $18,3 \%$ \\
$\mathbf{2 0 1 1}$ & $17,2 \%$ \\
\hline
\end{tabular}

Fonte: ETCO, IBRE/FGV (2011) 
Observa-se na tabela 1 que a participação da economia informal no Produto Interno Bruto (PIB) vem caindo nos últimos anos em função do bom momento econômico, mas, principalmente, pelo aumento do emprego formal e fortalecimento dos micronegócios, embora ainda seja significativa a presença informal na produção interna, com uma média de $20 \%$ do que é produzido com origem na economia informal (ETCO e IBRE/FGV, 2011).

Segundo dados da última pesquisa realizada pelo IBGE acerca dos postos de trabalho dispostos nas empresas formais e informais, no Brasil, existiam 10.335.962 empresas informais que ocupavam 13.860.868 pessoas, incluindo trabalhadores por conta própria, pequenos empregadores, empregados com e sem carteira de trabalho assinada, além dos trabalhadores não remunerados (IBGE, 2005). A seguir, pode-se observar a evolução do mercado informal na Tabela 02:

Tabela 02: Número de Empresas Não Agrícolas com Até 5 Empregados por Unidade da Federação

\begin{tabular}{lll}
\hline \multicolumn{1}{c}{$\begin{array}{c}\text { Unidades da } \\
\text { Federação }\end{array}$} & \multicolumn{2}{c}{ Número de Empresas não Agrícolas com até $\mathbf{5}$ empregados } \\
\cline { 2 - 3 } BRASIL & \multicolumn{1}{c}{ Formalizadas } & \multicolumn{1}{c}{ Setor Informal } \\
São Paulo & 10525954 & 10335965 \\
Minas Gerais & 2622793 & 2581820 \\
Rio de Janeiro & 1088064 & 1049774 \\
Bahia & 878774 & 863435 \\
Sergipe & 763939 & 752870 \\
\hline
\end{tabular}

Fonte: IBGE (2005)

Destaca ainda esse relatório a relação entre o número de microempresas não agrícolas e com até 5 empregados, formalizadas ou não, com ênfase para as principais regiões metropolitanas e o Estado de Sergipe. Observou-se, ainda, que os estados de São Paulo, Minas Gerais, Rio de Janeiro, Bahia e Rio Grande do Sul concentravam o maior percentual de empreendimentos, com $57,6 \%$ das empresas do setor informal e $56,8 \%$ do total das pequenas empresas investigadas, o que leva a concluir que para cada microempresa formalizada, existe uma não formalizada atuando no mercado.

No estudo do IBGE (2005), verificou-se, também, que a proporção de pessoas ocupadas nessas cinco unidades da federação representava 56,4\% dos 13,9 milhões de trabalhadores na informalidade. São Paulo, isoladamente, concentrava 25\% ou 2.581 .820 empresas informais, seguido de Minas Gerais, com 10,3\% ou 1.049.774 empresas; e Rio de Janeiro, com 8,4\% ou 863.435 empresas informais. Nesse sentido, o Estado de Sergipe apresentou 104.789 empreendimentos informais.

Para confirmar o número excessivo de empreendimentos informais, pode-se observar, através da Tabela 03, com dados do SEBRAE/DF (2010) e do Ministério da Fazenda (2010), a relação entre a quantidade de empresas formalizadas e a quantidade de empresas não formalizadas: 


\section{PERFIL DOS EMPREENDEDORES INDIVIDUAIS E CARACTERÍSTICAS DOS NEGÓCIOS FORMALIZADOS PELO PROGRAMA EI EM ARACAJU, SERGIPE}

Tabela 03: Empreendimentos Formalizados e Não Formalizados no Brasil

\begin{tabular}{ccc}
\hline MPE & Total & Base de Dados \\
\hline Formalizadas & 5.838 .070 & SEBRAE (2010) \\
Não formalizadas & 10335962 & \multicolumn{2}{c}{ Ministério da Fazenda (2010) } \\
Relação & & 1,77 \\
\hline
\end{tabular}

Fonte: SEBRAE (2010) e Ministério da Fazenda (2010)

Portanto, a análise dos dados confirma a relação de que para cada empresa formalizada existem, aproximadamente, duas não formalizadas, ou seja, que não possuem registro enquanto firma. Assim, esse universo de empreendimentos informais tem reflexo direto na economia, conforme explica Tiryaki (2008): as atividades do setor informal estão inter-relacionadas com as atividades do setor formal, assim, quanto maior for a participação do setor informal no PIB, maior será a vulnerabilidade da economia, pois as flutuações das atividades econômicas tendem a ser mais voláteis.

\section{Apoio aos pequenos negócios}

Os pequenos negócios apresentam alto grau de vulnerabilidade com relação a recursos financeiros, tecnológicos, falta de qualificação de mão de obra, conhecimento limitado de aspectos gerenciais, acesso a mercados, concorrência, entre outros (BORGE; FILION e SIMARD, 2008; DELMAR e SHANE, 2003). Para Cook, Belliveau e Sandberg (2004), as MPEs são descritas como negócios com capital limitado, operadas pelos seus proprietários, com poucos empregados e suscetíveis às mínimas variações de mercado. Assim, a utilização de programas de incentivo, especificamente nas fases iniciais de preparação para o lançamento de novos empreendimentos, ajuda no desenvolvimento e crescimento dos novos negócios.

Antes de iniciar um novo empreendimento, Santarelli e Vivarelli (2007) evidenciam que os empreendedores desconhecem parte dos custos envolvidos no futuro negócio, possuem apenas informações básicas sobre gestão e, na maioria das vezes, vão desenvolver suas habilidades gerenciais no cumprimento das rotinas diárias, ou seja, após ter passado da fase inicial de funcionamento do empreendimento.

Assim, os autores evidenciam que a criação de empresas é influenciada pelo engajamento do governo no apoio ao empreendedorismo, através de incentivos à concepção de novos projetos de empresas, que pode ser obtido através de mudanças na legislação, desenvolvimento de instituições de apoio, oferecimento de facilidades para a gestação de novas empresas (incubadoras de empresas), apoio à sobrevivência e crescimento dos micronegócios, através do acesso às redes de informação, consultoria e criação de incubadoras e de outros recursos.

Vargas-Hernández (2010) afirma que, para garantir condições de desenvolvimento às MPEs, é necessária a adoção de instrumentos de apoio, como políticas governamentais, redução de impostos para diminuir custos, detecção de mercados potenciais, capacitação para um melhor aproveitamento das oportunidades e acesso facilitado a crédito para investimento.

A manutenção dos empreendimentos já existentes é tão importante quanto a criação de novos empreendimentos, pois, na opinião de Baron e Shane (2007), empresas estabelecidas exploram melhor uma oportunidade do que novas empresas, por cinco motivos: curva de aprendizagem, reputação, fluxo de caixa, economias de escala e recursos complementares. 
Samujh (2011) considera que os recentes avanços tecnológicos e nas telecomunicações permitiram a criação de diversas oportunidades para os micronegócios. Como na maioria dos países os negócios são compostos por microempreendimentos, os governos locais buscam incentivar a formação e a sustentabilidade desses empreendimentos em favor da dinâmica de suas economias.

Na visão de Albagli e Maciel (2002), faz-se necessária a promoção de melhores condições locais para a criação de novos negócios, ações e políticas de desenvolvimento e de ampliação da competitividade, de mobilização de recursos para incrementar a dinâmica e a capacidade empreendedora local, especificamente no que concerne às empresas iniciantes.

Conforme Yumkella e Vinanchiarachi (2003), uma vez observadas as limitações das MPE's, os governos de diversos países, através de instituições provedoras de serviços de suporte a negócios, finanças e tecnologia, apoiam as MPE's em suas fragilidades e garantem uma participação, cada vez maior, na economia e melhores condições de sustentabilidade.

Segundo Schneider e Veugelers (2010), com medidas simples os países podem incentivar a economia através do incremento de determinados aglomerados de microempresas, como, por exemplo, com a criação de uma legislação especifica para o setor, protegendo contra a concorrência das grandes empresas, oferecendo, dessa forma, mais garantias de retorno sobre os recursos investidos. Irwin (2011) lembra que os projetos e programas desenvolvidos para dar suporte às MPE's, quer através de fundos de investimento, quer através do apoio direto para as empresas, precisam considerar os objetivos estratégicos dos negócios, que, muitas vezes, carecem de clareza, gerando resultados inesperados. É necessária, portanto, uma análise dos fundos de investimentos que apoiam as MPE's e verificar se estes oferecem uma formação básica de apoio, na forma de aconselhamentos, microfinanciamentos e suporte à comercialização.

Contudo, considerando-se as incertezas do ambiente competitivo, explicam Santarelli e Vivarelli (2007), que os incentivos governamentais aos pequenos negócios inovativos tornam-se ineficazes. Isso ocorre porque no início esses investimentos podem gerar um efeito "substituição", artificialmente suportando as empresas menos eficientes até o seu fechamento, mas gerando uma sobrecarga no sistema de suporte, como um todo.

Segundo o GEM de 2011, o Brasil apresenta condições desfavoráveis para a criação de negócios, mesmo considerando que o país tenha apresentado uma elevada Taxa de Empreendedores em Estágio Inicial (TEA), com 14,9\% (GEM, 2012). Percebe-se que essa taxa tem relação maior com fatores associados ao comportamento empreendedor como a mentalidade empreendedora, o ambiente social e cultural e o mercado consumidor, apresentando uma pequena relação com fatores associados a condições de negócios, como as políticas e programas governamentais, educação, capacitação, infraestrutura, capital formal, etc. Todavia, apesar de as condições macroeconômicas favorecerem o empreendedorismo, bem como a estabilidade dos indicadores econômicos e as projeções de crescimento, o Brasil precisa desenvolver condições ligadas às políticas de apoio ao empreendedorismo.

Souza e Mazzali (2008) argumentam que embora haja um considerável número de ações de apoio ao desenvolvimento das MPEs, no geral, essas ações não são definidas levando em consideração os diversos subsegmentos. Assim, os efeitos esperados de tais medidas podem não se concretizar. A explicação está tanto nas características de inserção das MPEs nos diversos segmentos em que atuam, que não seriam alcançadas por essas ações, quanto porque parte significativa dos benefícios pode não ser apropriada pelas empresas objeto dessas ações.

Mesmo considerando que existam diversas políticas voltadas para o apoio das MPEs, segundo o GEM (2012) existe um hiato entre as necessidades e a oferta de programas do 


\section{PERFIL DOS EMPREENDEDORES INDIVIDUAIS E CARACTERÍSTICAS DOS NEGÓCIOS FORMALIZADOS PELO PROGRAMA EI EM ARACAJU, SERGIPE}

governo, bem como uma distância entre as políticas e os programas implementados e o empreendedor.

\section{O Programa Empreendedor Individual - EI}

O SEBRAE (2011a), com o intuito de retirar da informalidade milhões de empreendedores e facilitar a abertura de novos negócios, instituíu a figura do 'Empreendedor Individual' (EI), por meio da Lei Complementar no 128/2008, que altera a Lei Complementar no 123/2006 (Lei Geral da MPE). Assim, com a publicação de Resoluções e Portarias específicas, os empreendedores que faturam até $\mathrm{R} \$ 60.000,00$ (Sessenta mil reais) por ano, não possuem participação em outra empresa como sócio ou titular e que empregam até um trabalhador, podem se formalizar como EI. Entre as principais vantagens do programa EI estão:

- $\quad$ Registro no Cadastro Nacional de Pessoas Jurídicas (CNPJ), o que facilita a abertura de contas bancárias, empréstimos e permite a emissão de Notas Fiscais;

- Enquadramento no Simples Nacional e isenção dos tributos federais (Imposto de Renda, PIS, Cofins, IPI e CSLL);

- Cobertura Previdenciária: acesso a benefícios como auxílio maternidade, auxíliodoença, aposentadoria por idade (no mínimo após 15 anos de contribuição), saláriomaternidade após carência, pensão e auxilio reclusão, mediante contribuição fixa mensal de R\$ 28,25 (comércio ou indústria) ou $\mathrm{R} \$ 33,25$ (prestação de serviços), que será destinado à Previdência Social e ao ICMS ou ao ISS;

- Baixo custo para contratação de até um empregado, pagando 3\% Previdência e 8\% FGTS do salário mínimo por mês, valor total de R $\$ 59,95$, em que o empregado contribui com 8\% do seu salário para a Previdência;

- Isenção de taxa do registro da empresa e concessão de alvará para funcionamento, que poderá ser emitido através da internet;

- $\quad$ Ausência de Burocracia: a única exigência para se manter como EI é uma declaração anual sobre o faturamento, que pode ser feita pela internet;

- Serviços Contábeis Gratuitos: no primeiro ano o EI poderá buscar uma rede de empresas contábeis que irão prestar assessoria de graça;

- Apoio Técnico do SEBRAE na organização do empreendimento, através da oferta de cursos e planejamentos de negócios com vistas a capacitar os empreendedores;

- $\quad$ Participação em compras governamentais, bastando apenas estar formalizado.

Dessa forma, a referida Lei permite, através de amparo jurídico/legal, disponibilizar informações e ofertar benefícios previdenciários, tributários e outros, objetivando atrair para a formalidade um grande volume de indivíduos que exercem suas atividades de maneira informal (BARROS et al., 2010).

Como finalidade econômica, o Programa EI busca minimizar as vulnerabilidades que os micro e pequenos empreendimentos apresentam diante do mercado capitalista, assim, limitações como acesso a recursos financeiros, tecnológicos, falta de suporte para qualificação profissional e organizacional, são absorvidas por essa camada da população que contribui significativamente para a economia (SILVA et al., 2010).

Além da finalidade econômica, o programa também possui suporte contábil, pois é fonte 
de geração de receitas para os cofres públicos. Na medida em que os empreendedores são formalizados a arrecadação tributária aumenta, traduzindo-se na principal fonte de recursos para o governo realizar suas funções básicas, subsidiando o amparo previdenciário ofertado aos empreendedores (SILVA et al., 2010). Contudo a finalidade contábil também contribui para a organização dos empreendimentos, pois, segundo IBGE (2005), 53\% das empresas informais pesquisadas em 2003 não faziam nenhum tipo de registro contábil e, em $36 \%$ delas, os proprietários desempenhavam essa função sem auxílio de contador, de modo a ficarem suscetíveis a erros por falta de qualificação técnica.

Conforme elucidam Silva et al. (2010), o foco social do Programa EI considera que os efeitos do desemprego não se restringem apenas aos aspectos econômicos, como a perda de rendimentos, mas que são reconhecidos também pelo agravamento dos problemas sociais, psicológicos e físicos que contribuem para a condição de exclusão do trabalhador no mercado de trabalho. Dessa forma, o atributo da formalidade permite ao empreendedor acessar recursos de suporte para o incremento do seu empreendimento, aumentando as possibilidades de sobrevivência do referido negócio.

Outro aspecto que contribui para a melhoria das condições sociais é citado por Fernandes (2010), que descreve o empreendedor formalizado como um profissional mais tranquilo para exercer suas atividades, pois agora seu negócio está legalizado, sem a necessidade de burlar a fiscalização, e com expectativa de apoio governamental, institucional e das instituições financeiras

No dizer de Barros et al (2010), o simples fato de o programa conferir uma condição de maior estabilidade aos empreendimentos, através do acesso facilitado a fatores de produção, permite ao trabalhador manter-se em sua ocupação e evita o agravamento de problemas sociais decorrentes do desemprego, pois, na maioria das vezes, o modelo capitalista de produção não gera espaços ocupacionais suficientes para atender a população em condições de trabalho.

Segundo o autor, a figura do EI deu suporte para que pessoas em situação de pobreza vislumbrassem uma forma legal e acessível de autossustento e de proteção social. Mesmo considerando que, em sua maioria, essas pessoas em situação de maior vulnerabilidade desenvolvam um empreendedorismo por necessidade (e não por oportunidade), 87\% dos EI beneficiários do Bolsa Família desejam tornar seus negócios em microempresas, ainda que isso implique em mais impostos e exigências.

Portanto, mesmo considerando os avanços que a legislação proporcionou, como vantagens e benefícios às MPE's nunca vivenciados na história, ainda assim, segundo o GEM (2012), existe uma distância entre as necessidades e a oferta de programas do governo, bem como uma distância entre as políticas e os programas implementados e o empreendedor, fato que limita o campo de ação do empreendedor, gerando descontinuidades no funcionamento dos empreendimentos.

Conforme informa o SEBRAE (2012), desde 2009 é intenso o fluxo de empreendedores que procuram o programa a fim de legalizarem o negócio, de modo que de julho de 2009 a abril de 2012 foram legalizados cerca de 2.056 .015 (dois milhões, cinqüenta e seis mil e quinze) empreendedores, sendo que só em 2011 foram 900 mil pessoas e em 2012, 350 mil. Esse resultado fez com que o número total de microempreendedores passasse de 1 milhão em abril de 2011 para 2,1 milhões em março de 2012, num ritmo de 80 mil registros por mês, de maneira que o Nordeste, a exemplo, participa com 21\% dos EIs e 17\% das MPEs (SEBRAE, 2012).

De acordo com os números do SEBRAE (2011a), a maioria dos empreendedores individuais, $57 \%$ já tinha um negócio na informalidade. Desses, a grande maioria $75 \%$ já possuía seu negócio informal há mais de dois anos e só se formalizou com a regulamentação da LC nº 


\section{PERFIL DOS EMPREENDEDORES INDIVIDUAIS E CARACTERÍSTICAS DOS NEGÓCIOS FORMALIZADOS PELO PROGRAMA EI EM ARACAJU, SERGIPE}

$128 / 2008$. Soma-se a isso o fato de um percentual relevante de empreendedores individuais ter advindo do mercado formal de trabalho e de outro grupo que estava desempregado e/ou recebendo benefícios sociais antes de se formalizar.

\section{O Programa Empreendedor Individual em Sergipe}

Sergipe ocupa $21.910,3 \mathrm{~km}^{2}$, o que corresponde a $0,26 \%$ da área nacional, em termos de extensão territorial, é o menor Estado do Brasil. Situado no Nordeste, representando 1,4\% do território da região, Sergipe limita-se ao Norte com o Estado de Alagoas (tendo como demarcador o rio São Francisco), ao Sul e a oeste com o Estado da Bahia e a Leste com o Oceano Atlântico. Sua população é estimada em 2.068.017 habitantes, respondendo por aproximadamente 1,1\% da população do país e 3,9\% da região, e uma densidade demográfica de $94,35 \mathrm{hab} / \mathrm{km}^{2}$, acima das médias do Nordeste $\left(34,1 \mathrm{hab} / \mathrm{km}^{2}\right)$ e do Brasil $(22,43$ $\mathrm{hab} / \mathrm{km}^{2}$ ),conforme contagem populacional 2010 do IBGE (IBGE, 2011).

O Índice de Desenvolvimento Humano (IDH) ${ }^{1}$ é um indicador que mede a qualidade de vida humana de um determinado país, região ou localidade, por meio dos indicadores longevidade, renda e educação. No período de 2002 a 2007, os índices de Sergipe estiveram acima dos do Nordeste, todavia, abaixo dos do Brasil.

O Estado de Sergipe se posiciona em quarto lugar no ranking dos estados que mais cresceram no país. 0 avanço na economia sergipana chegou a ser maior inclusive do que o crescimento médio do PIB regional, que ficou em 1\%, e do PIB nacional, que registrou queda de 0,3\% (SEPLAG, 2011).

Em Sergipe, desde o início do processo de formalização, em Sergipe, foram contabilizadas 9.078 (nove mil e setenta e oito) formalizações, que representam 0,8\% dos EI formalizados em todo o país. De acordo com a pesquisa realizada pelo SEBRAE/SE entre os EI que buscaram orientação para formalização, 52\% eram homens e 48\% mulheres, Observa-se uma predominância de faixa de 30 até 39 anos, que responde por 33,6\% dos Empreendedores Individuais. A segunda faixa etária mais expressiva é a de 40 até 49 anos, com 25,4\% dos empreendedores, seguida pela terceira faixa etária de 25 até 29 anos, com 16,8\% dos EI. Verifica-se a predominância das atividades de comércio e serviços nas EI em Sergipe, que, por apresentarem menores exigências, como conhecimento técnico, infraestrutura, e licenças para funcionamento, têm a sua entrada facilitada no mercado (SEBRAE, 2011a).

\section{Metodologia}

Este estudo se caracteriza como exploratório e descritivo: o caráter exploratório se justifica em função de ser o primeiro a ser realizado em Sergipe sobre o tema abordado e se propõe desenvolver hipóteses e proposições que irão redundar em pesquisas complementares; já o descritivo, por caracterizar os empreendedores individuais, descrever as características dos empreendimentos formalizados através o Programa EI em Aracaju, Sergipe.

Este estudo adota uma estratégia quantitativa, com a utilização do método survey. Esse método, conforme Babbie (2001), permite a elaboração de enunciados descritivos sobre o público alvo, que admite como foco adicional fazer asserções explicativas sobre a população estudada. Para realizar a Survey, foi aplicado pelo pesquisador desse estudo um questionário como instrumento de coleta de dados, composto por questões fechadas baseados nas variáveis e indicadores do quadro 01.

\footnotetext{
${ }^{1}$ Varia de zero a um. Quanto mais próximo do valor $1(\mathrm{um})$ mais desenvolvido é a localidade ou o País.
} 
Quadro 01: Variáveis e Indicadores do Perfil do Empreendedor e Características dos Negócios

\begin{tabular}{|c|c|c|}
\hline Variáveis & Indicadores & Unidade de Análise \\
\hline \multirow{15}{*}{$\begin{array}{c}\text { Perfil do } \\
\text { Empreendedor } \\
\text { Individual }\end{array}$} & \multirow{2}{*}{ Gênero } & -Masculino; \\
\hline & & - Feminino. \\
\hline & \multirow{5}{*}{ Faixa Etária } & - De 20 a 30 anos; \\
\hline & & - De 30 a 40 anos; \\
\hline & & - De 40 a 50 anos; \\
\hline & & - De 50 a 60 anos; \\
\hline & & - Mais de 60 anos. \\
\hline & \multirow{3}{*}{ Escolaridade } & $\begin{array}{l}\text { Fundamental Incompleto ou } \\
\text { Completo; }\end{array}$ \\
\hline & & $\begin{array}{l}\text { Ensino Médio ou } \\
\text { Médio/Técnico; }\end{array}$ \\
\hline & & $\begin{array}{l}\text {-Pós-Graduação/Superior } \\
\text { Incompleto ou Completo; }\end{array}$ \\
\hline & \multirow{2}{*}{ Renda Média Mensal } & Menos de R\$2000; \\
\hline & & $\begin{array}{c}\text { De R\$ } 2000,00 \text { até } \mathrm{R} \$ \\
10.000,00\end{array}$ \\
\hline & \multirow{3}{*}{ Ocupação anterior à formalização } & Desempregado; \\
\hline & & $\begin{array}{l}\text { - Trabalho com ou sem carteira } \\
\text { assinada; }\end{array}$ \\
\hline & & $\begin{array}{l}\text { - Negócio atual sem estar } \\
\text { formalizado; }\end{array}$ \\
\hline \multirow{9}{*}{$\begin{array}{l}\text { Características do } \\
\text { Negócio }\end{array}$} & \multirow{3}{*}{ Tipo de Atividade Econômica } & - Indústria \\
\hline & & - Comércio \\
\hline & & -Serviço \\
\hline & \multirow[t]{2}{*}{ Tempo de Atividade no Ramo } & Até 2 anos \\
\hline & & Acima de 2 anos \\
\hline & \multirow{2}{*}{$\begin{array}{l}\text { Quantidade de pessoas que } \\
\text { trabalham no negócio além do } \\
\text { proprietário }\end{array}$} & - Nenhuma \\
\hline & & -Uma ou mais \\
\hline & \multirow{2}{*}{$\begin{array}{l}\text { Familiares Dependentes da Renda } \\
\text { gerada pelo Negócio }\end{array}$} & •Nenhum; \\
\hline & & - Um ou mais; \\
\hline
\end{tabular}

Fonte: Elaborados pelos pesquisadores (2012)

O universo dessa pesquisa, segundo o SEBRAE (2011), foram 9.078 (nove mil e setenta e oito) empreendedores individuais formalizados desde o início do Programa EI em Sergipe, em junho de 2009. Foi considerado para esse estudo os que tinham pelo menos um ano com o empreendimento registrado, a fim de que o empreendedor tivesse a percepção acerca das ações desenvolvidas pelo programa do EI e do desempenho do seu negócio após a formalização. No que tange à delimitação do tamanho da amostra a ser estudada, adotou-se uma amostra probabilística, delimitada por meio do cálculo da fórmula expressa por Barbetta (1994) abaixo elucidada:

$$
A=\frac{M * M 0}{M+M 0}
$$

Onde: $\mathrm{A}=$ Amostra;

$\mathrm{M}=$ População Total;

$\mathrm{M} 0$ = Aproximação $\left(1 / \mathrm{E}^{2}\right)$, sendo $\mathrm{E}^{2} \mathrm{o}$ erro amostral; 


\section{PERFIL DOS EMPREENDEDORES INDIVIDUAIS E CARACTERÍSTICAS DOS NEGÓCIOS FORMALIZADOS PELO PROGRAMA EI EM ARACAJU, SERGIPE}

Assim, o cálculo do M0 (1/ $\left.\mathrm{E}^{2}\right)$ revelou um resultado de aproximadamente 278, obtido por: 1 / $0,06^{2}$. Tal resultado, ao ser aplicado à formula da amostragem proposta por Barbetta (1994), resultou em: 9.078*278 / 9.078+278, o qual teve como resultado o número amostral de 300. Sendo assim, foram aplicados questionários a trezentos empreendimentos individuais, sendo obtido um retorno total, a fim de assegurar resultados mais próximos da realidade, permitindo alcançar um coeficiente de segurança de 95,5\%, com uma margem de erro de aproximadamente 5\%.

Os dados coletados por meio dos questionários são apresentados a seguir por meio de estatística descritiva assim como a respectiva análise que serviram de suporte para atender os objetivos do estudo.

\section{Características dos empreendedores individuais}

As características dos empreendedores individuais foram analisadas a partir dos seguintes indicadores: sexo, faixa etária, escolaridade, renda mensal e a ocupação do empreendedor anterior à formalização. Esses indicadores caracterizaram os aspectos pessoais dos empreendedores individuais, em que é relevante lembrar que esses empreendedores possuem, pelo menos, um ano de experiência com seu negócio formalizado.

O presente estudo buscou identificar a participação por gênero entre os empreendedores formalizados através do Programa EI em Sergipe. Seguindo tal afirmativa, na Tabela 04 pode-se visualizar que a distribuição percentual entre os gêneros masculino e feminino é $49 \%$ e $51 \%$, respectivamente.

Tabela 04: Gênero do Empreendedor Individual (EI)

\begin{tabular}{c|c|c}
\hline GÊNERo & Frequência Absoluta & Frequência Relativa (\%) \\
\hline Masculino & 147 & 49,0 \\
Feminino & 153 & 51,0 \\
\hline Total & 300 & 100 \\
\hline
\end{tabular}

Fonte: Pesquisa de Campo (2012)

Ao se compararem os resultados dispostos na Tabela 04 com o estudo dos empreendedores individuais feito pelo SEBRAE (2012), percebe-se um resultado ligeiramente diferente, pois do total de EIs registrados no Brasil, o SEBRAE aponta que 54\% são homens e $46 \%$ mulheres. Apesar dessa leve diferença e conforme reforçado na pesquisa aqui realizada em Sergipe, de acordo com dados do IBGE (2005), existe uma tendência de equilíbrio entre os gêneros pelo fato de as mulheres cada vez mais assumirem o comando das famílias, responsabilizando-se, também, pelo sustento das unidades familiares.

Esses resultados também se assemelham aos encontrados pelo GEM (2012), acerca do gênero dos empreendedores iniciais. O GEM expõe que de 2001 a 2011, entre os empreendedores iniciais, o percentual de homens se manteve em 52,82\% e o de mulheres em $47,18 \%$, resultado esse um pouco similar ao apontado na pesquisa aqui realizada, se diferenciando pelo fato desse estudo apresentar um percentual de mulheres discretamente superior a de homens. Já para os empreendedores estabelecidos, o GEM (2012) apontou um 
percentual de 59,99\% para o gênero masculino e 40,01\% para o feminino, nos anos de 2002 e 2011, destoando dos resultados aqui encontrados e do percentual encontrado nos empreendedores iniciais apontados pelo GEM em 2011.

Entretanto, essa diferença se torna significativamente maior quando comparados os resultados da Tabela 11 com os de divisão por gênero dos microempresários, conforme o estudo do SEBRAE (2011a) sobre os microempresários, o qual pode ser visualizado na Figura 06 apresentada anteriormente, que demonstra que a participação das mulheres no universo de microempresários é de $29 \%$ e os dos homens de $71 \%$. Já os empreendedores individuais apresentaram um percentual similar ao encontrado nessa pesquisa, com 55\% de empreendedores homens e 45\% de empreendedores mulheres (SEBRAE, 2011a).

Com relação à faixa etária dos EIs em Sergipe, observa-se, por meio da Tabela 05, que a faixa de maior predominância se encontra entre os 30 e os 40 anos, com 35\% de representatividade, seguida pela de 40 a 50 anos, com um percentual de 30,30\%, revelando que o empreendedor individual é relativamente jovem. Os achados dessa pesquisa são similares aos encontrados pelo SEBRAE (2011a), o qual apontou que 33\% dos EIs apresentam entre 30 e 40 anos.

Tabela 05: Faixa Etária dos EI's em Sergipe

\begin{tabular}{|c|c|c|}
\hline FAIXA ETÁRIA & Frequência Absoluta & Frequência Relativa (\%) \\
\hline 20 a 30 anos & 66 & 22,0 \\
\hline 30 a 40 anos & 105 & 35,0 \\
\hline 40 a 50 anos & 91 & 30,3 \\
\hline 50 a 60 anos & 33 & 11,0 \\
\hline Mais de 60 anos & 5 & 1,7 \\
\hline Total & 300 & 100 \\
\hline
\end{tabular}

Fonte: Pesquisa de Campo (2012)

Ao se comparar os resultados dessa pesquisa com os do SEBRAE (2012), referente aos empreendedores individuais, nota-se que a faixa etária apontada pelo SEBRAE com maior representatividade é a de 30 a 39 anos, com 33\% dos microempreendedores individuais; seguida pela faixa de 40 a 49 anos, com 23,6\% dos empreendedores; a de 25 a 29 anos, com $15,8 \%$ dos MEI, demonstrando que os empreendedores individuais são relativamente jovens, com cerca de $60 \%$ deles com menos de 40 anos.

Vale ademais considerar que, ao se compararem esses resultados com os da faixa etária dos microempresários apresentada em pesquisa realizada pelo SEBRAE (2011a), nota-se que a faixa etária dos microempresários gira em torno de 40 anos. Dessa maneira, é possível inferir que a figura do Empreendedor Individual tem servido como "porta de entrada" dos jovens no empreendedorismo, em que esses se deparam com a possibilidade de montar seu próprio negócio. Corroborando com o exposto, os resultados divulgados pelo GEM (2012), em relação à faixa etária dos empreendedores iniciais, revelaram uma maior concentração nas faixas etárias entre 25 e 34 anos, com 17,85\%, e 35 e 44 anos, com 17,24\%. 


\section{PERFIL DOS EMPREENDEDORES INDIVIDUAIS E CARACTERÍSTICAS DOS NEGÓCIOS FORMALIZADOS PELO PROGRAMA EI EM ARACAJU, SERGIPE}

De acordo com Silva et al. (2010), o nível de escolaridade constitui um importante fator gerador de produtividade para o microempreendedor, influenciando diretamente as práticas e ações desenvolvidas no âmbito do negócio. Na Tabela 06, pode-se verificar que o grau de escolaridade predominante entre os EIs é ensino médio ou ensino médio técnico, com 38,3\% das afirmações; seguido por 35,7\%, com ensino fundamental completo ou incompleto; e 26\%, com pós-graduação ou nível superior completo ou incompleto.

Tabela 06: Escolaridade dos EI's

\begin{tabular}{l|c|c}
\hline \multicolumn{1}{c|}{ Escolaridade } & $\begin{array}{c}\text { Frequência } \\
\text { Absoluta }\end{array}$ & $\begin{array}{c}\text { Frequência Relativa } \\
\text { (\%) }\end{array}$ \\
\hline Fund. Incompleto/Completo & 107 & 35,7 \\
\begin{tabular}{l|c} 
Médio/Técnico \\
Superior Completo/ Incompleto/
\end{tabular} & 115 & 38,3 \\
Pós & 78 & 26,0 \\
\hline \multicolumn{1}{c}{ Total } & 300 & 100 \\
\hline
\end{tabular}

Fonte: Pesquisa de Campo (2012)

Em comparação com a pesquisa nacional do SEBRAE (2011a), que trata do nível de escolaridade dos microempreendedores, representada na Figura 4, cujo resultado apontou para 47\% com nível médio/técnico, 36\% com fundamental incompleto/completo e 17\% com nível superior completo/incompleto ou pós-graduação, observa-se que os EIs sergipanos possuem uma distribuição semelhante, com mais ou menos empreendedores nos mesmos níveis que os apontados pela pesquisa do SEBRAE (2011a); diferenciam-se entretanto, por apresentarem um percentual consideravelmente elevado de empreendedores com algum tipo de nível superior, se comparados com o apontado pelo estudo nacional do SEBRAE.

Já no estudo do SEBARE (2012), a escolaridade encontrada para os EIs foi de: 0,8\% sem educação formal; 34,7\% com fundamental incompleto/completo; 48,5\% com ensino médio ou técnico completo; 15,8\% com nível superior completo/incompleto ou pós-graduação, concentração essa semelhante à encontrada nessa pesquisa. Vale considerar também que o nível de escolaridade médio/técnico e superior da pesquisa aqui realizada se aproxima do apresentado pelo GEM (2012), cujos percentuais são 42,09\% e 17,92\%, respectivamente, seguindo, portanto, a tendência observada no país.

$\mathrm{Na}$ Tabela 07 , pode-se verificar que mais da metade dos entrevistados, cerca de $54 \%$, se recusou a indicar uma faixa de renda mensal auferida. Contudo, entre os EIs que indicaram a renda mensal, 21,3\% afirmaram receber até $R \$ 2.000,00$, e 24,7\% mais de $R \$ 2.000,00$. 
Tabela 07: Renda Mensal do EI

\begin{tabular}{l|c|c}
\hline \multicolumn{1}{c|}{ Renda Mensal } & Frequência Absoluta & Frequência Relativa (\%) \\
\hline Não responderam & 162 & 54,0 \\
Até R 2.000 & 64 & 21,3 \\
De R \$ 2.000 a 10.000 & 74 & 24,7 \\
\hline \multicolumn{1}{c}{ Total } & 300 & 100 \\
\hline
\end{tabular}

Fonte: Pesquisa de Campo (2012)

Observa-se que, entre os respondentes, as taxas se mantiveram equilibradas, com ligeira predominância nos EIs que obtêm acima de R\$2.000,00. Ao se comparar esse resultado com os demonstrados pela pesquisa FECOMÉRCIO/SEBRAE-DF (2009), a qual identificou que cerca de $79,6 \%$ dos Empreendedores Individuais possuem renda inferior a $R \$ 2.000,00$, no primeiro momento pode-se inferir que os EIs sergipanos possuem melhores condições financeiras, fato que favorece a manutenção da estrutura familiar e evita o comprometimento dos recursos financeiros dos empreendimentos. Entretanto, tal afirmativa não pode ser comprovada por não se conhecer a renda mensal dos não respondentes. Ao se comparar com os dados do GEM (2012), observa-se dentro da mesma faixa de renda analisada, um resultado de 49,19\% para aqueles que possuem renda de até $\mathrm{R} \$ 2.000,00$ e de $50,81 \%$ para os que estão acima de $\mathrm{R} \$$ $2.000,00$, resultado esse também equilibrado.

Na Tabela 08, pode-se verificar que $41.3 \%$ dos entrevistados estavam trabalhando com carteira assinada antes da formalização do seu negócio, seguido por 35\% que possuíam o atual negócio sem formalizá-lo, $15 \%$ que não possuíam carteira assinada, 5,3\% estavam desempregados e $3,4 \%$ se recusaram a responder.

Tabela 08: Ocupação Anterior a Formalização

\begin{tabular}{|c|c|c|}
\hline Ocupação Anterior a Formalização & $\begin{array}{c}\text { Frequência } \\
\text { Absoluta }\end{array}$ & $\begin{array}{c}\text { Frequência } \\
\text { Relativa (\%) }\end{array}$ \\
\hline Sem resposta & 10 & 3,4 \\
\hline Desempregado & 16 & 5,3 \\
\hline Trabalho c/ carteira assinada & 124 & 41,3 \\
\hline Trabalho sem carteira assinada & 45 & 15,0 \\
\hline Negócio atual sem estar formalizado & 105 & 35,0 \\
\hline Total & 300 & 100 \\
\hline
\end{tabular}

Fonte: Pesquisa de Campo (2012)

Diferente dos resultados expostos na Tabela 15, a pesquisa nacional do SEBRAE (2011a) demonstrou que a maioria dos empreendedores individuais, 57\%, já possuía o seu negócio de 


\section{PERFIL DOS EMPREENDEDORES INDIVIDUAIS E CARACTERÍSTICAS DOS NEGÓCIOS FORMALIZADOS PELO PROGRAMA EI EM ARACAJU, SERGIPE}

maneira informal; 31\% estavam empregados com ou sem carteira assinada antes de se formalizar; e $12 \%$ estavam desempregados. Assim, pode-se verificar que, em Sergipe, é maior o número de EI que estava trabalhando com ou sem carteira assinada e que existe uma quantidade menor de negócios informais.

Já os resultados apontados pelo SEBRAE (2012) apontaram: 38\% estavam empregados com carteira assinada; $25 \%$ estavam empregados sem carteira assinada; 23\% estavam desempregados; e 15\% já possuíam seu negócio. Percebe-se que os resultados demonstrados pelo SEBRAE (2012) são diferentes aos encontrados nessa pesquisa, apresentando maior divergência nas taxas de empreendedoresindividuais desempregados e que já possuíam um negócio.

\section{Características dos negócios}

As características dos empreendimentos são analisadas pelos indicadores: atividade econômica; tempo de atividade no ramo; pessoas que trabalham no negócio além do proprietário; e familiares dependentes da renda gerada pelo negócio. É relevante lembrar que esses empreendimentos possuíam pelo menos um ano de funcionamento desde a sua formalização.

Pode-se observar, através da Tabela 09, que grande parte dos entrevistados, 72,67\%, atuava no ramo do comércio, $26 \%$ no de serviços e apenas $1,33 \%$ na indústria.

Tabela 09: Atividade Econômica

\begin{tabular}{|c|c|c|}
\hline Tipo de Atividade Econômica & $\begin{array}{c}\text { Frequência } \\
\text { Absoluta }\end{array}$ & $\begin{array}{c}\text { Frequência Relativa } \\
\text { (\%) }\end{array}$ \\
\hline Comércio & 217 & 72,67 \\
\hline Indústria & 4 & 1,33 \\
Serviço & 78 & 26,00 \\
\hline Total & 300 & 100 \\
\hline
\end{tabular}

Fonte: Pesquisa de Campo (2012)

Ao se compararem os resultados desta pesquisa com os do estudo nacional do SEBRAE (2011a), pode-se verificar que, nesse último, o setor industrial teve maior representação, com 17,6\%; já como a observada no setor de serviços foi 35,6\%. Essa situação se inverte quando se compara a representação do setor de comércio, pois, no estudo nacional, foi de apenas 39,5\%, diante dos $72,67 \%$ observados neste estudo. Da mesma forma, na pesquisa com os empreendedores individuais realizada pelo SEBRAE (2012), o comércio apresentou um percentual de 39\%; o setor de serviços com 36\%; a indústria, com 17\%; e a construção civil, com $8 \%$.

0 alto percentual encontrado no comércio e a discrepância com a pesquisa nacional e a do SEBRAE (2012) podem ser influenciados pelo fato de, no Estado de Sergipe, segundo o anuário do SEBRAE (2011a), existirem 16.917 (dezesseis mil, novecentos e dezessete) pequenos empreendimentos no setor do comércio, 8.687 (oito mil, seiscentos e oitenta e sete) no setor de serviços e 4.844 (quatro mil, oitocentos e quarenta e quatro) no setor da indústria e construção civil. Assim, os percentuais aqui encontrados seguem a tendência de concentração de 
empreendimentos de pequeno porte nos referidos setores de atividade econômica.

Ademais, a pequena participação da indústria nos resultados da presente pesquisa pode ser explicada pelo fato de os entrevistados considerarem que as atividades que exercem possuem características artesanais em algumas etapas do processo produtivo, o que levaria a considerar que atuam no setor de serviços e não da indústria.

Na Tabela 10, pode-se verificar que a grande maioria dos entrevistados afirmou possuir mais de dois anos na atividade, com $86,27 \%$ da amostra; os restantes 13,67\% menos de dois anos.

Tabela 10: Tempo na Atividade

\begin{tabular}{l|c|c}
\hline Tempo na Atividade & Frequência Absoluta & Frequência Relativa (\%) \\
\hline Até 02 anos & 41 & 13,67 \\
Acima de 02 anos & 259 & 86,27 \\
\hline \multicolumn{1}{c}{ Total } & 300 & 100 \\
\hline
\end{tabular}

Fonte: Pesquisa de Campo (2012)

Quando se compara com os dados do estudo nacional do SEBRAE (2011), observa-se que $42 \%$ dos EIs atuam na atividade há no máximo dois anos, dado bem mais elevado do que o encontrado nesta pesquisa, com 13,67\%. Esse resultado também é diferente entre os que trabalham há mais de dois anos, uma vez que, no estudo do SEBRAE nacional, chegou a 41\% e em Sergipe foi de 86,27\%. Os resultados apresentados neste estudo revelam, portanto, que são poucos os empreendimentos recentes em Sergipe se comparados com o percentual apontado pela pesquisa nacional do SEBRAE (2011).

A diferença de resultados pode ter sido influenciada pelo fato de que, segundo dados do SEBRAE (2011), a taxa de mortalidade das empresas em Sergipe é superior à média do país, o que significa dizer que, no Estado, 32\% das MPEs fecham antes de completar dois anos, enquanto, no Brasil, essa taxa é de $22 \%$, o que revela, portanto, as vulnerabilidades a que esses empreendimentos estão expostos, principalmente, nos primeiros anos de funcionamento, os quais conforme o SEBRAE (2011) corresponde tipicamente ao período mais frágil da empresa frente ao mercado.

Pode-se observar por meio da Tabela 11 que 21\% dos respondentes não têm funcionários, trabalhando, portanto, sozinhos; 79\% têm um ou mais funcionários em seu empreendimento.

Tabela 11: Pessoas no Negócio

\begin{tabular}{c|c|c}
\hline $\begin{array}{c}\text { Pessoas que Trabalham no } \\
\text { Negócio além do Proprietário }\end{array}$ & $\begin{array}{c}\text { Frequência } \\
\text { Absoluta }\end{array}$ & $\begin{array}{c}\text { Frequência Relativa } \\
\text { (\%) }\end{array}$ \\
\hline Nenhuma & 63 & 21,0 \\
Uma ou mais & 237 & 79,0 \\
\hline Total & 300 & 100 \\
\hline
\end{tabular}

Fonte: Pesquisa de Campo (2012) 


\section{PERFIL DOS EMPREENDEDORES INDIVIDUAIS E CARACTERÍSTICAS DOS NEGÓCIOS FORMALIZADOS PELO PROGRAMA EI EM ARACAJU, SERGIPE}

Entretanto, quando se observa o resultado do estudo nacional realizado pelo SEBRAE (2011a), verificam-se resultados bem diferentes dos expostos na Tabela 18, de forma que a grande maioria dos empreendedores individuais, 87\%, não conta com nenhum empregado, enquanto os outros $13 \%$ contam com pelo menos um funcionário.

Constata-se, então, grande diferença em relação aos resultados encontrados na pesquisa de Sergipe, pois a maioria dos EIs sergipanos, 79\%, conta com a ajuda de pelo menos um funcionário. Tal resultado pode ser explicado pelo perfil do empreendedor individual em Sergipe por Segmento de atividade, SEBRAE (2011a), disposto na Tabela 10, em que se pode observar que os tipos de segmentos de atividades necessitam, conforme evidenciaram os entrevistados, de funcionários, em virtude do ramo de atividade, a exemplo do comércio. Outro fator que pode explicar tal diferença reside nas características das empresas sergipanas, nas quais a inserção de familiares no negócio é prática comum, característica presente nos micronegócios (SEBRAE/DF, 2009).

Na Tabela 12, pode-se observar que $81 \%$ dos entrevistados afirmaram que seus familiares dependem da renda gerada pelo negócio, de modo que apenas 19\% dos respondentes não têm familiares que dependem de sua atividade.

Tabela 12: Familiares Dependentes da Renda Gerada pelo Negócio

\begin{tabular}{c|c|c}
\hline Familiares Dependentes & Frequência Absoluta & Frequência Relativa (\%) \\
\hline Nenhum & 57 & 19,0 \\
Um ou mais & 243 & 81,0 \\
\hline Total & 300 & 100 \\
\hline
\end{tabular}

Fonte: Pesquisa de Campo (2012)

Da mesma forma, estudo realizado pelo SEBRAE (2009), no Distrito Federal, identificou que $84,5 \%$ dos empreendedores daquela localidade tinham familiares dependentes do negócio, enquanto apenas 15,5\% indicaram não ter nenhum familiar dependente da renda.

Assim, pode-se inferir, a partir dos resultados verificados nesta pesquisa e na do Distrito Federal, que a maioria dos EIs (81\%), em Sergipe, sustenta seus familiares com a renda gerada pelo seu empreendimento, confirmando a característica de distribuição de renda inerente aos empreendimentos individuais.

\section{Considerações finais}

Essa pesquisa delineou o perfil dos empreendedores individuais que participaram do Programa EI assim como caracterizou os empreendimentos desses empreendedores na cidade de Aracaju, Sergipe. Pode-se destacar inicialmente a expressiva participação feminina que é proporcional à participação masculina, o que demonstra que a atuação da mulher no gerenciamento desses empreendimentos é significativa, a exemplo dos resultados encontrados na pesquisa GEM (2012) .

A faixa etária predominante entre os EI foi de 30 a 40 anos de idade, devendo-se destacar que a maioria possui até 40 anos, revelando perfil jovem entre os pesquisados. Por sua vez, a 
escolaridade se mostrou bem distribuída, mas com predominância na faixa do ensino médio ou técnico. Nesse aspecto chama a atenção do expressivo número de EI em Sergipe com escolaridade superior que é bem acima dos percentuais encontrados no estudo nacional ou mesmo no GEM. A baixa renda mensal individual parece ser baixa, mas esse resultado não deve ser analisado sem considerar que a maioria não informou a renda que recebe como resultado do seu negócio.

Chama a atenção o elevado percentual de EI que estava empregado com ou sem carteira assinada antes de se formalizar, 56,3\%. Uma possível explicação para esse número é que, dada a facilidade de abrir um empreendimento, em virtude da Lei do Empreendedor Individual, muitos indivíduos que já estavam formalizados como empregados resolveram iniciar seu próprio negócio, embora haja um percentual de 5,3\% de empreendedores individuais que estavam desempregados antes de se formalizar.

Em relação aos empreendimentos, são predominantes no setor do comércio, seguidos pelo setor de serviços, sendo pouco representativos os do setor industrial. Esses resultados diferem da pesquisa do SEBRAE nacional, que teve representação mais equilibrada entre os setores.

Os EI desse estudo contam com ajuda de uma ou mais pessoas, o que demonstra já deterem certo nível de distribuição de tarefas; resultado esse bem distinto do encontrado na pesquisa nacional. A grande maioria detém experiência no ramo acima de dois anos, de modo que foram poucos os empreendimentos que surgiram recentemente; há a predominância expressiva de um ou mais familiares dependentes da renda gerada pelo empreendimento, de maneira que o negócio, mais do que uma fonte de renda individual, se torna o sustento dos familiares do dono do negócio.

Como recomendações para novas pesquisas, sugere-se também a realização de um estudo comparado com microempreendedores formalizados pelo Programa EI e não formalizados, a fim de verificar quais os reais benefícios e dificuldades por eles enfrentados. Por fim, sugere-se que o estudo aqui realizado seja replicado, no intuito de comparar a evolução dos empreendimentos com sua situação atual e verificar se esses empreendimentos se mantiveram no decorrer do tempo.

\section{Referências}

ALBAGLI, S.; MACIEL, M. L. Capital Social e Empreendedorismo Local. Políticas para Promoção de Sistemas Produtivos Locais de MPME. Rio de Janeiro. 2002.

BABBIE, E. Métodos de Pesquisas de Survey. Belo Horizonte: Editora UFMG, 2001.

BARBETTA, P. A. Estatística Aplicada às Ciências Sociais. Florianópolis: UFSC, 1994.

BORGES, C.; FILION, L. J.; SIMARD, G. Jovens Empreendedores e o Processo de Criação de Empresas. Revista de Administração Mackenzie, vol. 9, n. 8, 2008.

BARON, R. A.; SHANE. S. A. Empreendedorismo: uma visão do processo. São Paulo: Thomson Learning, 2007.

BARROS, Ricardo; CARVALHO, Mirela; FRANCO, Samuel; MENDONÇA, Rosane. Determinantes na Queda da Desigualdade de Renda no Brasil. IPEA: Rio de Janeiro, 2010.

CACCIAMALI, M. C. Setor informal urbano e formas de participação na produção. São Paulo: IPE/USP, 144 p. (Tese de Doutorado), 1983.

CACCIAMALI. M. C. \& BRAGA, T. Políticas públicas voltadas para o setor informal. IN: CHAHAD, 


\section{PERFIL DOS EMPREENDEDORES INDIVIDUAIS E CARACTERÍSTICAS DOS NEGÓCIOS FORMALIZADOS PELO PROGRAMA EI EM ARACAJU, SERGIPE}

J.P.Z. (coord.) Estudos e análise com vistas à definição de políticas, programas e projetos relativos ao mercado de trabalho brasileiro. São Paulo: FIPE/MTE, janeiro, 2002, 82p. (Relatório de Pesquisa).

COOK, R. G.; BELliVEAU, P.; SANDBERG, M. E. Training and Learning as Drivers of US Microenterprise Business Plan Quality. Education \& Training, vol. 46, n. 8/9, pp. 398-405, 2004.

DELMAR, F.; SHANE, S. Does Business Planning Facilitate the Development of New Ventures? Strategic Management Journal, vol. 24, n. 12, pp. 1165-1185, 2003.

FECOMERCIO/SEBRAE-DF. Estudo econômico das micro e pequenas empresas, 2009. Disponível em: <www.sebrae.com.br>. Acesso em 18 jan. 2012.

FERNANDES, J. C. O Microempreendedor Individual (MEI): vantagens e desvantagens do novo sistema. Revista Eletrônica de Direito do Centro Universitário Newton Paiva, vol. 1, p. 16, 2010.

GEM, Global Entrepreneuship Monitor. The Global Entrepreneurship Monitor. Curitiba: IBPQ, 2012.

GOMES, J. A.; FREITAS, A. A. F.; CAPELO JÚNIOR, E. O retrato do empreendedor informal. In: ENCONTRO NACIONAL DE ENGENHARIA DE PRODUÇÃo (ENEGEP), 25, Porto Alegre, out./nov. 2005.

IBGE, Instituto Brasileiro de Geografia e Estatística. ECONOMIA INFORMAL URBANA 2003. ISBN 85-240-3807-1, Rio de Janeiro. 2005.

IBGE. Censo Populacional do Brasil. 2011. Disponível em:

http://www.censo2010.ibge.gov.br/

IBRE/FGV, Instituto Brasileiro de Economia da Fundação Getúlio Vargas. Conjuntura econômica, 2011. Disponível em: <http://portalibre.fgv.br/>. Acesso em: 22 jan. 2012.

IRWIN, D. Learning from business support in Africa. Management Research Review, vol. 34, $\mathrm{n}$. 2, pp. 207-220, 2011.

KANTIS, H.; ISHIDA, M.; KOMORI, M.. Empreendedorismo em economias emergentes: criação e desenvolvimento de novas empresas na América Latina e no Leste Asiático. Banco Interamericano de Desenvolvimento, 2002.

KREIN, J. D.; PRONI, M. W.. Economia informal: aspectos conceituais e teóricos. Organização Internacional do Trabalho: Escritório da OIT no Brasil, 2010.

LEI COMPLEMENTAR no 123, de 14 DE DEZEMBRO DE 2006, Brasília. Disponivel em: <http://www.sebrae.com.br/customizado/lei-geral/lei-geral/legislacao/lei-geral-na-integra>. Acesso em: 20 jun. 2011.

MATTOS, E.; OGURA, L. M. Skill differentiation between formal and informal employment. Journal of Economic Studies, Vol. 36, n. 5, pp. 461 - 480, 2009. 
Ministério da Fazenda. Empreendimentos informais, 2010. Disponível em: <www.fazenda.gov.br>. Acesso em: 26 jan. 2012.

Ministério do Trabalho e Emprego (MTE). A informalidade no mercado de trabalho brasileiro e as políticas públicas do governo federal, 2002. Disponível em: <http://portal.mte.gov.br/data/files/FF8080812BA5F4B7012BABBAC51731E4/Informalidade 2.pdf>. Acesso em: 20 jun. 2011.

OYELARAN-OYEYINKA, B.; LAL, K. Learning New Technologies By Small And Medium Enterprises In Developing Countries. Maastricht. Technovation, vol. 26, pp. 220-231, 2004.

SAMUJH, H. Micro-businesses need support: survival precedes sustainability. Corporate Governance, vol. 11, n. 1, pp. 15-28, 2011.

SANTARELLI, E.; VIVARELLI, M. Entrepreneurship and the process of firms' entry, survival and growth. Industrial and Corporate Change, vol. 16, nº 3, pp. 455-488, 2007.

SCHNEIDER, C. Mixed R\&D incentives: the effect of R\&D subsidies on patented inventions. Working Papers, vol, 06, 2008.

SCHNEIDER, C.; VEUGELERS, R. On young highly innovative companies: why they matter and how (not) to policy support them. Industrial and Corporate Change, vol. 19, n. 4, pp. 9691007, 2010.

SEBRAE. Fatores Condicionantes e Taxas de Sobrevivência e Mortalidade das Micro e Pequenas Empresas no Brasil 2003-2005, Brasília. SEBRAE, 2007.

SEBRAE; DIEESE. Anuário do Trabalho na Micro e Pequena Empresa. 2008-2009. 3. ed. /Serviço Brasileiro de Apoio às Micro e Pequenas Empresas (Org.); Departamento Intersindical de Estatística e Estudos Socioeconômicos[responsável pela elaboração da pesquisa, dos textos, tabelas e gráficos]. -Brasília, DF; DIEESE, 2009.

SEBRAE/PR. Estudo econômico das micro e pequenas empresas, 2010. Disponível em: $<$ www.sebrae.com.br>. Acesso em 18 jan. 2012.

SEBRAE. Anuário do trabalho na micro e pequena empresa: 2010-2011. 4. ed. /Serviço Brasileiro de Apoio às Micro e Pequenas Empresas (Org.); Departamento Intersindical de Estatística e Estudos Socioeconômicos[responsável pela elaboração da pesquisa, dos textos, tabelas e gráficos]. -Brasília, DF; DIEESE, 2011a.

SEBRAE. Taxa de sobrevivência das empresas no Brasil. Brasília: SEBRAE, 2011b.

SEBRAE. Perfil do Microempreendedor Individual 2012. Série Estudos e Pesquisas: SEBRAE, 2012.

SEPLAG. Notícias - PIB: Sergipe é o quarto estado que mais cresceu em 2009. Disponível em: http://www.seplag.se.gov.br/noticias/1211-pib-sergipe-e-o-quarto-estado-que-maiscresceu-em-2009 Acesso em: 10 de dezembro de 2011

SILVA, N.; et. al. A importância do empreendedor rural para capacitar, desenvolver e equacionar estrategicamente os recursos sustentáveis, gerando renda e qualidade de vida. Revista eESTUDANTE - Electronic Accounting and Management Universidade Tecnologica Federal 
do Paraná, Campus Pato Branco , 2010.

SOUZA, M. C. A. F; MAZZALI, L. Conceito e Espaço da Pequena Empresa na Estrutura Industrial: heterogeneidade e formas de inserção. Gestão e Produção, vol. 15, n. 3, p. 591-603, set./dez. 2008.

TIRYAKI, G. F. A informalidade e as flutuações na atividade econômica. Estudos Econômicos, vol. 38, n. 1, 2008.

VARGAS-HERNANDEZ, J. G. Can Handcrafts Micro Business in Southern San Sebastian Compete Well? Research in Applied Economics, vol. 2, n. 2, 2010.

VIOTTI, E. B. Technological Learning Systems, Competitiveness and Development. International Conference on Technological Innovation and Development: Massachusetts, 2004.

YUMKELLA, K.; VINANCHIARACHI, J. Leading issues on Africa's path to industrialisation: The role of support systems and instruments. Journal of African Economies, vol. 12, n. 10, pp. 3040, 2003. 